\title{
A PERCEPÇÃO DOS ESTUDANTES SOBRE O ENSINO DA RESPONSABILIDADE SOCIAL CORPORATIVA NA GRADUAÇÃO EM ADMINISTRAÇÃO
}

\author{
UNDERGRADUATE STUDENTS' PERCEPTION OF CORPORATE SOCIAL \\ RESPONSIBILITYIN ADMINISTRATION COURSES
}

Recebido em: 16/11/2012 - Aprovado em: 08/02/2013 Avaliado pelo sistema double blind review Editora Científica: Manolita Correia Lima

\section{JONATHAN PEREIRA DOS SANTOS jonathan_psan@yahoo.com.br RENATA CÉLI MOREIRA DA SILVA PONTIFÍCIA UNIVERSIDADE CATÓLICA DO RIO DE JANEIRO}

\begin{abstract}
RESUMO
O tema Responsabilidade Social Corporativa (RSC) tem sido cada dia mais abordado pela mídia e por pesquisadores acadêmicos. Porém, ainda há uma carência nos estudos sobre o ensino da RSC nas faculdades de Administração. A investigação do ensino é importante, pois estes alunos serão os futuros gestores de empresas. Sendo assim, o artigo investigou a percepção dos alunos sobre o ensino da RSC na graduação em Administração, por meio de entrevistas em profundidade com treze estudantes de duas faculdades do Rio de Janeiro. Foi observado que os entrevistados acreditam saber sobre o que significa Rsc, e pode-se perceber, ao darem as suas definições, que elas são muito superficiais. Os resultados também apontam que muitos alunos consideram que deveria haver mais espaço para o tema nas faculdades, principalmente em relação à prática. Entretanto, foi visto que uma das faculdades alterou sua grade curricular recentemente, incorporando uma disciplina obrigatória dedicada ao tema.
\end{abstract}

Palavras-chave: Responsabilidade Social Corporativa, ensino, Administração.

The Corporate Social Responsibility (CSR) topic has aroused the interest of the media and of academics around the world. However, administration schools still lack classes that teach the subject. Since these students will be the next corporate managers, a deep study of this teaching issue should be better investigated. This study investigated undergraduate administration students' perception of how CSR is taught, using in depth interviews with thirteen students from two universities in Rio de Janeiro. It was found that the students believe they know what CSR means, but their definitions of it were very superficial. The results of this study also show that many students feel that this issue should receive better, more prominent coverage at universities, especially as regards its practice. However, one of the surveyed universities has recently changed its curriculum to include an obligatory class on CSR.

Keywords: Corporate Social Responsibility; Education; Business Administration.
} 


\section{INTRODUÇÃO}

O Dinamismo da economia mundial, aliado ao crescimento tecnológico, é responsável por um crescimento acelerado na difícil rotina dos negócios empresariais. Com isso surge a necessidade de se repensar a maneira pela qual era atingido esse crescimento econômico demandado, tendo como foco o desenvolvimento social e ambiental (ASHLEY, 2002). É nesse cenário - de se fazer mais socialmente, ambientalmente e economicamente - que aumenta cada vez mais a pressão para que as empresas sejam socialmente responsáveis (AGUILERA et al., 2007; MARQUIS; GLYNN; DAVIS, 2007). As empresas buscam destacar o que tem sido feito por elas de forma socialmente responsável (SERRA; ALBERNAZ; FERREIRA, 2007). Empresas que se comportam irresponsavelmente têm suas imagens corporativas prejudicadas (HOND; BAKKER, 2007). É notório o destaque da Responsabilidade Social, nos dias de hoje, além de ser praticamente inquestionável a sua relevância para a sociedade.

Para Melo Neto e Froes (200I), a empresa socialmente responsável deve estar inserida na comunidade que exista na vizinhança, introduzindo um novo elemento a essa sociedade: a cidadania empresarial e a Responsabilidade Social. A aplicação no segmento corporativo desta prática, segundo Schommer e Rocha (2007), é fundamental, já que ela pode ser vista como solucionadora de problemas ligados ao desenvolvimento ambiental e social.

Com essa importância e evidência da Responsabilidade Social no cenário atual, é relevante que as instituições de ensino de Administração, responsáveis pela formação de futuros gestores, estejam atualizadas no sentido de ensinar e incorporar no dia a dia das salas de aula o assunto Responsabilidade Social. Pesquisas já foram realizadas sobre o ensino desse tema na graduação em Administração (SILVA; CHAUVEL, 20IO; SILVA; CHAUVEL, 20II), mostrando-se, porém, ainda um campo de estudo incipiente. Assim, o presente artigo tem o objetivo de investigar a percepção dos estudantes de Administração em relação ao ensino da Responsabilidade Social Corporativa. Para tanto, foram entrevistados alunos de duas faculdades de Administração na cidade do Rio de Janeiro, uma faculdade privada e outra pública. 
REVISÃO DA LITERATURA

\section{A RESPONSABILIDADE SOCIAL CORPORATIVA (RSC)}

A conceituação do termo Responsabilidade Social Corporativa (RSC) ainda não é tão simples, tendo em vista que é um assunto ainda pouco maturado e que ainda encontra diversas vertentes (MATTEN; MOON, 2008). Para Machado Filho (2006, p. 24), "confunde-se, muitas vezes, responsabilidade social com "ações sociais", reduzindo seu escopo com atividades de cunho filantrópico". O que exemplifica ainda mais essa dificuldade.

Machado Filho (2006) cita a definição da organização não governamental Business for Social Responsibility (BSR), principal entidade mundial na área de RSC, que, de forma geral, define a RSC como decisões embasadas nos valores éticos e que também envolvem as dimensões legais, humanas, comunitárias e ambientais, como pode ser visto na citação a seguir.

O BSR Institute sustenta que o conceito de empresa socialmente responsável se aplicará àquela que atue no ambiente de negócios de forma que atinja ou exceda as expectativas éticas, legais e comerciais do ambiente social na qual a empresa se insere (MACHADO FILHO, 2006, p. 25).

Aprofundando mais na definição de RSC, Carroll (I99I) propõe subdivisões, a saber: dimensões econômica, legal, ética e filantrópica. Para Enderle e Tavis (I998), as subdivisões da RSC seriam: econômica, ambiental e social. De acordo com Melo Neto e Froes (200I) e Ashley (2002), a Rsc engloba tanto o público interno quanto o público externo da organização. Essa visão é a chamada visão socioeconômica e que leva em conta os stakeholders das empresas, ou seja, as empresas devem praticar a RSC considerando os diversos públicos a quem afeta, como meio ambiente, comunidade etc (MARrewijk, 2003). Complementando essa visão, os autores McWillians e Siegel (200I) sublinham que a Rsc é aquilo que a empresa realiza em termos de ações na sociedade e que vai além do que é realmente sua obrigação (além da lei exigida, por exemplo).

Outro grande indicador da relevância da RSC é em relação à percepção do tema pela comunidade, que, segundo Bonatto, Mauss e Magalhães (2007), é 
utilizada como estratégia de diferenciação para a imagem da organização e, assim, é capaz de criar novas demandas e posicionar o produto/serviço de uma forma Premium. Bowen (2007) também afirma que as empresas vêm passando a adotar a RSC como estratégia, e fazendo aportes de recursos para atingir objetivos e obter vantagens competitivas.

Santos (2008) destaca a busca da legitimação da organização por meio da RSC e afirma que uma empresa que pratica a RSC pode se tornar também uma organização mais estruturada institucionalmente e operacionalmente. Santos (2008) também pondera que, apesar de estrategicamente benéfica, a organização não deve tomar o lugar do Estado na promoção social, minimização de danos e no desenvolvimento sustentável, mas sim trabalhar em conjunto. Esse é um ponto muito discutido por muitos autores.

A RSC tem sido tão enfatizada por empresas, pela mídia e pelos pesquisadores, que vem gerando maior demanda de pesquisas sobre o tema. Alguns assuntos que estão sendo bastante investigados pelos pesquisadores são: como as empresas praticam a RSC (BANSAL; ROTH, 2000; KÄRNÄ; HANSEN; JUSLIN, 2003; SOUZA; DREHER; AMAL, 2007; ROCHA et al., 2008), se os consumidores valorizam as empresas socialmente responsáveis (SEN; BHATTACHARYA, 20OI; VOLPON; CRUZ, 2004; BECKER-OLSEN; CUDMORE; HILL, 2006; NAN; HEO, 2007; CHAN; WONG; LEUNG, 2008; FERREIRA; AVILA; FARIA, 2OIO; MELO; FARIAS, 20I2).

\section{ENSINO DA RESPONSABILIDADE SOCIAL CORPORATIVA}

Como foi dito no item anterior, há diversas pesquisas no meio acadêmico sobre a prática da RSC. Porém, essas pesquisas, em sua maioria, possuem o foco na aplicação do tema na prática das empresas, em suas estratégias, nas áreas de marketing e até se esse fator influencia no consumo dos indivíduos. Entretanto, pouquíssimas pesquisas no Brasil buscam investigar a percepção dos alunos sobre o ensino de RSC nos cursos de administração (SILVA, 2009). Há a necessidade de se investigar como o tema é visto em Administração e se é percebido como construtivo e eficiente na formação profissional. Como os estudantes de hoje serão os administradores de amanhã e poderão estar ocupando cargos que envolvam situações com questões éticas e sociais 
(CANOPF; PASSADOR, 2004), é preciso investigar se esse ensino está sendo satisfatório.

Silva (2006, p. 5) também é enfática ao afirmar o papel das universidades e a importância dos administradores na construção da RSC nas empresas, como pode ser visto no trecho a seguir:

Estudantes de administração formarão, provavelmente, a classe de futuros dirigentes empresariais. Aprendem a liderar pessoas, a elaborar projetos e a gerenciar recursos e tempo, a planejar e cumprir prazos, a calcular custos, investir lucros etc. Incentivando a prática da responsabilidade social, a escola além de espaço de reprodução e criação do saber tornar-se-á também um espaço de transformação, e dialeticamente, essas transformações poderão modificar o processo de ensino - aprendizagem.

A seguir, serão resumidos alguns estudos existentes sobre o ensino da RSC na graduação em Administração, realizados no Brasil:

- Silva (2006): A autora, que iniciou o trabalho em 1999, teve como objetivo analisar e aproximar os alunos de uma instituição de ensino superior, verificando se eles poderiam desenvolver e envolver pessoas num programa de voluntariado, de forma continuada. Usando uma metodologia de pesquisa-ação, método comum em pesquisas sobre educação, faz com que esse seja um artigo, que é ao mesmo tempo expositivo em relação a questões de promoção social das instituições de ensino superior, mas também promotor e relator de ações sociais. Um dos resultados mais relevantes foi em relação ao papel pouco ativo das instituições de ensino em promover práticas de ações sociais, na conduta socialmente responsável e até na formação de alunos.

- Medeiros, Borges e Sá (2007): O artigo busca investigar a percepção do aluno de administração sobre o tema, com um estudo de natureza quantitativa e que foi realizado na cidade de Uberlândia, contemplando duas instituições de ensino: uma instituição pública e outra privada, e busca aprofundar o tema, tendo como base as três dimensões da RSC, a econômica, social, e ambiental. Os resultados mostraram que os alunos acreditam na necessidade de construção de uma sociedade melhor; no entanto, para eles, o desenvolvimento social do país cabe 
à esfera governamental. Outro ponto relevante é a contrariedade em relação à percepção dos conceitos da RSC, mostrando diferença entre o que é falado e aquilo que é praticado, além do pouco interesse no assunto.

- Silva (2009), Silva e Chauvel (2010) e Silva e Chauvel (20II): A dissertação de mestrado de Silva (2009) posteriormente foi publicada em uma revista por Silva e Chauvel (20II). Foi uma pesquisa sobre a percepção dos estudantes de graduação em Administração em relação ao ensino da RSC. Foram feitas entrevistas em profundidade com alunos de cinco faculdades do estado do Rio de Janeiro. Os resultados mostraram que os alunos consideram que as faculdades tratam o tema de forma superficial. O tema possui pouco espaço nas faculdades e, de acordo com os alunos, deveria ser mais bem abordado, principalmente tendo uma disciplina obrigatória e um ensino voltado para a prática. Essa pesquisa foi complementada por um estudo quantitativo feito pelas autoras Silva e Chauvel (2010) e os resultados corroboraram o estudo anterior.

- Ferreira, Ferreira e Faria (201I): O objetivo do artigo foi investigar a percepção dos alunos de Administração em relação ao ensino da Ética, que é uma das dimensões da RSC, de acordo com Carroll (199I). Foram feitos grupos focais com estudantes de uma faculdade privada do Rio de Janeiro. Os resultados apontaram que os alunos dão importância ao ensino da Ética. Para eles, uma disciplina na faculdade seria relevante para que os estudantes refletissem sobre o tema; porém, eles enfatizaram que não seria a disciplina de Ética responsável por moldar os comportamentos dos alunos, já que a postura ética de um indivíduo deve ter sido moldada anteriormente. Mas, de qualquer forma, seria fundamental para gerar discussão em sala de aula. Além disso, eles entendem que o tema Ética deve constar das demais disciplinas da grade curricular. 


\section{METODOLOGIA}

Por se tratar de um tema pouco explorado na literatura brasileira, foi feito um estudo exploratório. De acordo com Gil (1987, p. 4I), esse tipo de pesquisa tem o objetivo de "proporcionar maior familiaridade com a questão problema, com vistas a torná-lo mais explícito ou a construir hipóteses”. Como é um tema ainda embrionário, a pesquisa busca aprofundar esse fenômeno e entendê-lo mais profundamente.

De acordo com os autores Fraser e Gondim (2004, p. 8), na abordagem qualitativa, o que se pretende, além de conhecer as opiniões das pessoas sobre determinado tema, é entender as motivações, os significados e os valores que sustentam as opiniões e as visões de mundo. Em outras palavras é dar voz ao outro e compreender de que perspectiva ele fala.

Dada a natureza qualitativa do estudo, foram realizadas entrevistas em profundidade com treze estudantes de administração de duas faculdades, uma pública e uma privada. As entrevistas foram feitas guiadas por um roteiro semiestruturado de pesquisa. Vieira e Tibola (2005, p. I3) ressaltam as vantagens da entrevista em profundidade, tais como: "resposta isenta da influência do grupo", "a informação é mais completa e detalhada”, "é flexível, permitindo modificações no processo de entrevista", "informações confidenciais são mais fáceis de se obter”.

A construção do roteiro foi feita com base na revisão da literatura, considerando estudos anteriores sobre o tema. $\mathrm{O}$ estudo em que mais se baseou o desenvolvimento do roteiro foi o de Silva (2009) e de Silva e Chauvel (20II). Nesse contexto, o roteiro semiestruturado de pesquisa abordou, de forma geral, os seguintes temas: visão sobre o conceito RSC; existência de uma disciplina sobre o tema; abordagem do tema nas demais disciplinas; espaço dado ao tema nas faculdades; sugestões sobre como abordar o tema em sala de aula e formar gestores socialmente responsáveis.

Para o presente artigo, foram entrevistados treze alunos de duas universidades (uma pública e uma particular) - duas universidades que foram as pesquisadas por Silva (2009) e Silva e Chauvel (20II). Porém, os nomes das faculdades não foram divulgados, para garantir o anonimato 
e a integridade do estudo. Inclusive, ao avisar para os entrevistados que o nome das universidades não seria divulgado, eles poderiam se tornar mais tranquilos para conversar e expor suas opiniões reais, ao invés de proteger a universidade em que estudam.

Os entrevistados foram selecionados por conveniência. Foram realizadas entrevistas com alguns estudantes conhecidos e estes indicaram outros. O critério para participar da entrevista foi ter se formado há, no máximo, dois anos ou estar próximo do período de formatura (máximo um ano). Esse critério foi escolhido para que não houvesse o risco de entrevistar indivíduos que se formaram há muito tempo e que, por isso, pudessem ter esquecido muitos pontos importantes da época de faculdade, ou o risco de entrevistar alguém que ainda não está perto de se formar e, por isso, pode não conhecer a totalidade de disciplinas que a faculdade oferece no curso de graduação em administração.

Os entrevistados, assim como os nomes das faculdades, não foram identificados, sendo seus nomes substituídos por siglas. Dessa forma, para quem era da faculdade particular teve seu nome substituído por AI, A2, $\mathrm{A}_{3}$ e assim por diante. Para quem era da faculdade pública teve seu nome substituído por $\mathrm{BI}, \mathrm{B} 2, \mathrm{~B} 3$, e assim por diante. 


\section{ANÁLISE DOS RESULTADOS}

\section{PERFIL DOS ENTREVISTADOS}

Foram entrevistados I3 indivíduos, sendo sete homens e seis mulheres, entre eles, nove estudantes de administração com a previsão de formatura até dezembro de 2013 e quatro ex-alunos formados há menos de dois anos em administração.

Na Tabela I, é apresentado um sumário das principais características dos entrevistados: gênero, idade, tipo de instituição, período de formatura e se o estudante/administrador trabalha.

Tabela I Sumário do perfil dos entrevistados

\begin{tabular}{|llllll|}
\hline Entrevistado & Gênero & Idade & Instituição & Formatura & Cargo \\
\hline A1 & Masculino & 24 & Privada & 2012.2 & Analista de Marketing \\
\hline A2 & Feminino & 25 & Privada & 2011.2 & Analista de Marketing \\
\hline A3 & Masculino & 26 & Privada & 2011.2 & Consultor \\
\hline A4 & Feminino & 21 & Privada & 2013.1 & Estagiária \\
\hline A5 & Masculino & 22 & Privada & 2013.2 & Estagiário \\
\hline A6 & Feminino & 22 & Privada & 2013.1 & Estagiária \\
\hline A7 & Masculino & 24 & Privada & 2013.1 & Analista de Compras \\
\hline A8 & Feminino & 22 & Privada & 2013.1 & Estagiária \\
\hline B1 & Masculino & 21 & Pública & 2013.1 & Estagiário \\
\hline B2 & Feminino & 23 & Pública & 2013.2 & Não trabalha \\
\hline B3 & Masculino & 24 & Pública & 2013.1 & Não trabalha \\
\hline B4 & Feminino & 22 & Pública & 2012.1 & Trainee \\
\hline B5 & Masculino & 23 & Pública & 2012.1 & Consultor \\
\hline
\end{tabular}

\section{O QUE O ALUNO ENTENDE SOBRE RSC}

Foi possível observar que muitos entrevistados conseguiram dar, de forma geral, alguma definição do que é a RSC, apesar de muitas não serem as definições completas, baseadas na visão socioeconômica da RSC, incluindo os diversos stakeholders. Vale pontuar também que quando perguntados 
se o tema ainda causava algum tipo de dúvida, vários entrevistados foram enfáticos em constatar que não havia dúvidas claras sobre o tema. Somente poucos participantes mencionaram a existência de dúvidas.

É possível observar também, com base nas respostas dadas pelos participantes, um certo senso de propriedade dos alunos sobre o tema, talvez pelo acesso constante a dados e informações sobre o assunto ou até pelo relacionamento diário que alguns têm com a Rsc, em suas empresas. Porém, mesmo com esse conhecimento e com a impressão de que eles tinham um senso de propriedade no assunto e a falta de dúvidas, as definições podem ser enquadradas como superficiais e incompletas, já que, em muitos casos, englobava-se apenas uma das dimensões da RSC. Como visto na revisão da literatura, o termo RSC, de acordo com a visão socioeconômica, envolve várias dimensões, como a econômica, ambiental e social (CARROLL, I99I; MELO NETO; FROES, 200I). Levando isso em consideração, observou-se que diversos entrevistados não tinham essa amplitude do tema em mente.

Em alguns casos, listados nos depoimentos a seguir, as definições foram feitas, levando apenas em conta aspectos sociais. Porém, também foram citadas definições ligadas às dimensões econômica e ambiental.

"Uma empresa que se preocupa com o bem-estar da sociedade em que está inserida e que realiza projetos sociais...” (A3).

"Entendo que é como a empresa age para reduzir os impactos sociais no ambiente que atua. Eu acho que, além disso, trazer uma boa imagem pra empresa, eu acho que esse é motivo principal de elas terem a responsabilidade social; deveria ser obrigatório elas possuírem essa responsabilidade de acordo com sua função e proporcional aos danos.” (A4).

"Se preocupar com a comunidade envolvida (...) o ambiente que sua empresa está envolvida. Acho o tema muito importante." (A6).

"Entendo como um conjunto de ações que a empresa tem para ajudar no meio social onde esta se encontra. Na minha opinião, muitas destas ações são tomadas com o objetivo de dar visibilidade para a empresa (ser vista com uma empresa que colabora com a sociedade e não visa somente lucro e benefícios próprio.) “( $\mathrm{BI})$.

"Responsabilidade social corporativa para mim são todas as ações da empresa 
que tem como fim o benefício da sociedade." (B2).

"São ações sociais praticadas pelas empresas em prol da comunidade. Acho de extrema importância, pois pode auxiliar tanto para a comunidade, por meio, por exemplo, de melhorias na infraestrutura, quanto pra própria empresa com um impacto positivo na sua imagem, mão de obra local, entre outros." (B3)

Outro fato relevante neste item foi a associação do conceito de RSC a uma ferramenta de marketing, voltada para "dar visibilidade para a empresa" (entrevistado BI), elucidando algumas opiniões dos participantes, que veem a RSC também como uma ferramenta para causar "um impacto positivo na sua imagem" (entrevistado B3), mostrando que pode ser mais uma forma de divulgar a imagem da empresa do que somente alguma preocupação com a sociedade. Alguns alunos fizeram uma crítica ou desabafo em relação à falta de credibilidade que as empresas têm em relação à prática real da Rsc, mostrando que não acreditam totalmente num discurso responsável das organizações.

Esses resultados também foram percebidos por Silva (2009) e Silva e Chauvel (20II), que relataram essa superficialidade na definição de Rsc pelos estudantes de graduação. As autoras também mostraram que os conceitos englobavam somente algumas dimensões da RSC, como a econômica definida por Carroll (2004), ambiental e social - definida por autores como Ashley (2002).

\section{PERCEPÇÕES DOS ALUNOS SOBRE O ENSINO DE RSC E SUA ABORDAGEM EM SALA DE AULA}

Este item irá mostrar a percepção dos alunos sobre o ensino da RSC em sala de aula, tendo como foco saber se havia uma matéria destinada ao tema, ou se outras matérias abordavam o assunto, mesmo que por meio de exemplos ou trabalhos para a turma.

Quando perguntados sobre a existência de alguma disciplina que abordasse a Responsabilidade Social, houve algumas respostas diferentes, que eram recebidas com alguma estranheza, no primeiro momento, pelos pesquisadores, pois os alunos entrevistados da universidade particular 
afirmaram ter uma matéria sobre o tema e os alunos da universidade pública e os alunos formados da universidade particular, afirmaram não ter nenhuma disciplina sobre o mesmo tema. A estranheza foi causada pela divergência entre as respostas dos alunos que estão cursando a faculdade particular e os que já se formaram nela, pois enquanto uns falavam que havia a disciplina outros falavam que não havia. Porém, foi logo percebido que essa divergência se deu por causa da mudança na grade curricular dessa faculdade, que tinha uma disciplina de RSC como eletiva e, após a mudança, ela se tornou obrigatória e os atuais alunos precisam cursá-la. Ou seja, os alunos já formados da faculdade particular não tiveram obrigatoriedade em cursar essa disciplina e, por isso, disseram que ela não existia.

Um depoimento interessante foi o da entrevistada A2, que mostrou que ela era da grade curricular antiga, quando não era obrigatória essa disciplina e, apesar de ter conhecimento da existência dessa matéria, ela optou por não fazê-la em detrimento de outras ligadas à sua área de interesse.

Essa mudança na grade curricular pode ser vista como uma mudança positiva, mostrando a importância que o tema vem ganhando e que futuramente pode virar uma tendência nas instituições de ensino. Uma vez que a repercussão sobre o tema vem aumentando e a RSC vem assumindo cada vez mais importância no cenário corporativo, pode ser que somente a inclusão da disciplina na grade curricular, de forma obrigatória, garanta o cumprimento da disciplina pelos alunos.

Todos os alunos que cursaram a disciplina afirmaram que a cursaram por ser uma disciplina obrigatória, mas continuam suas respostas expressando suas opiniões favoráveis a respeito:

“Eu fiz porque ela é obrigatória e gostei porque ela trouxe vários assuntos que envolvem ética corporativa e como gerir uma organização frente à sociedade onde ela atua, algo que todas as empresas estão sujeitas" (AI).

"Sim. Porque faz parte do currículo e faz com que tenhamos uma visão diferente em como preservar a organização fazendo com que fique valorizada pela sua postura em relação à sociedade.” (A5)

"Sim, porque era obrigatória, mas acho que faria sem ser, pois acho importante." (A6). 
"Fiz porque é obrigatória, e achei interessante" (A7).

“Estou Cursando, porque é obrigatória, acho que são informações relevantes para todo mundo, até mesmo além de quem faz ADM ou trabalha em empresas." (A8).

E ainda continuando, quando perguntados sobre o que haviam achado da disciplina e qual tinha sido a sua contribuição para sua formação, muitos afirmaram:

"Contribuiu, pois me instruiu melhor a qual o papel que a organização onde trabalho deve ter perante a sociedade, o que eu como empresário devo saber sobre conduta externa. Não me lembro de algo que não tenha gostado” (Ar). "Acho que contribui muito, pois cita conceitos importantes relacionados ao tema” (A4).

"Para dar embasamento teórico e estudar caso com empresas que tiveram problemas e sucessos." (A6).

Porém outros acrescentaram expressando sua frustração com a aula:

"Nada" (A8)

"O que não gostei da disciplina foi querer só usar slides para dar aula. Acredito que é uma matéria que precisa de prática, seja experimental.” (A5)

Essas respostas mostraram um pouco da contradição dos alunos de administração a respeito do tema, à medida que todos os que cursaram a disciplina afirmaram que a fizeram por ser obrigatória, e pontuam isso em sua declaração (ou seja, não fizeram a disciplina porque queriam e sim pela obrigatoriedade). Essas contradições também foram encontradas por Silva (2009) e Silva e Chauvel (20II). Apesar disso, a maioria ressalta algum beneficio em ter feito, como se tentasse crer na relevância dela na formação. Ou seja, eles falaram que cursaram porque a disciplina é obrigatória e não pelo interesse, mas mesmo assim afirmam que ela agregou conhecimento sobre o tema. Por outro lado, alguns citaram que a disciplina não contribuiu tanto, por ser muito teórica e com pouco ensino da prática do tema. Esses resultados corroboram os estudos de Silva (2009), Silva e Chauvel (2010) e Silva e Chauvel (20II), mostrando que os alunos dão importância para o ensino da prática da RSC. 
Ainda avaliando as repostas dos alunos da instituição privada, quando perguntados sobre outras disciplinas que abordam o tema, a maioria aponta a disciplina "Ética profissional" como outra matéria que possui esse assunto em pauta. Porém alguns alunos afirmam também ter percebido o tema em outras disciplinas:

"Quase todas as matérias de marketing e ética" (A8)

"Sim. Matérias de marketing como princípios de marketing, gerência de marketing e comportamento do consumidor." (A5)

"Matérias voltadas à Gestão de Negócios e Organizações como um todo sempre abordam, mesmo que superficialmente, o tema." (A2)

Já em relação à faculdade pública, o fato de não terem tido uma disciplina sobre o tema, fez com que a maioria desses alunos, negasse ou desqualificasse o pouco contato com o tema em outras disciplinas:

"Pouco abordado. Na parte de RH, mas nada especifico." (B2)

"Não tem, mas tive um professor que usava a matéria dele e pedia que o trabalho fosse um trabalho social." (B4)

Quando perguntado se foi feito algum trabalho sobre o tema, a maioria negou ter feito ou afirmava não lembrar ao certo do trabalho, demonstrando um pouco do desinteresse sobre ele e da pouca abordagem dada ao tema. $\mathrm{Na}$ instituição pública, a maioria dos alunos citou uma atividade de cunho social como trabalho sobre Rsc.

Finalizando a percepção do aluno sobre o ensino da Rsc, de forma geral, os alunos da instituição particular afirmam considerar o espaço dado para o tema RSC adequado, por causa da grade curricular nova que incorporou uma disciplina obrigatória sobre o tema. No entanto, os alunos da universidade pública afirmam de forma categórica que o espaço não é suficiente, chegando a afirmar que:

"Não, porque na verdade é inexistente, e deveria ser algo para estimular os jovens a se mobilizarem dentro das próprias empresas/corporações.” (B3)

"Não. É muito pouco abordado, e sempre como sendo algo secundário para a formação profissional." (BI)

Comparando com Silva (2009) e Silva e Chauvel (201I), que afirmaram que os estudantes de administração consideram o espaço para abordar o tema 
insuficiente nas faculdades, foi possível observar na presente pesquisa que, apesar do tema ainda ser considerado por alguns alunos como de baixa visibilidade nas disciplinas do curso de administração, já é possível observar alguma mudança nas respostas, uma vez que o ensino de RSC já é obrigatório na nova grade curricular do curso de administração da faculdade privada.

\section{PERCEPÇÕES E SUGESTÕES SOBRE A FORMAÇÃO DOS GESTORES SOCIALMENTE RESPONSÁVEIS}

Esse item procurou investigar a percepção do aluno de administração acerca da eficiência dos cursos na formação de um gestor socialmente responsável e as sugestões dos alunos para que uma faculdade possa abordar o tema em sala de aula.

Quando perguntados se a faculdade em que estudaram/estudam é capaz de formar gestores socialmente responsáveis, foi possível perceber muitas respostas diferentes. Entre elas, é válido ressaltar a resposta dos entrevistados Ar, A7, B2, B3 e B4, dos quais Ar e A7 são alunos da faculdade particular, e $\mathrm{B}_{2}, \mathrm{~B}_{3}$ e $\mathrm{B}_{4}$ da universidade pública. Esses entrevistados concordam que é possível que a sua instituição de ensino forme gestores socialmente responsáveis, justificando que a formação, no geral, depende do aluno e de conhecimento externos:

"Na minha opinião, sim, mas isso é algo que vai da conduta de cada um, independentemente do que a faculdade ensina apesar de achar que ela passa os conceitos necessários nesse assunto” (AI)

"Acredito, porque a geração que tá se formando agora é bem voltada para essa parte de responsabilidade social...” (A7)

"Acho que muitas vezes um gestor socialmente responsável não depende da formação de ensino superior. Mas formação fundamental e familiar em grande parte dos casos. A faculdade pode orientar melhor em formas de fazê-lo. Mas quem quer ser socialmente responsável tem outras maneiras de alcançar êxito que não seja pela faculdade” (B2)

"Sim, porque hoje essa questão não depende só da faculdade. Existem maneiras por meio de iniciativas dos próprios alunos que podem colaborar 
nesse sentido." (B3)

“(....) acho que a formação não de um gestor, mas de um indivíduo socialmente responsável tenha que acontecer antes disso, em casa e no colégio para quando entrar na faculdade e começar os primeiros estágios, o indivíduo já ter interesse pelo tema." (B4)

Essa visão dos alunos de que a formação socialmente responsável de uma pessoa vem desde antes da faculdade, por meio dos valores aprendidos ao longo da vida, por exemplo, é um discurso semelhante ao observado por Ferreira, Ferreira e Faria (20II), que mostrou que os alunos consideram o ensino da Ética importante nas faculdades, mas que não é essa disciplina que irá definir se o gestor vai ser ético ou não, pois essa formação moral ocorre ao longo da vida e não depende somente de uma matéria na faculdade.

Ainda, observando os demais alunos provenientes da universidade pública, sobre a percepção de formação de gestores socialmente responsáveis por suas faculdades, fica explícito que a fragilidade da grade curricular da instituição, que não apresenta matérias sobre RSC e não tem muitas matérias tratando o assunto, faz com que os participantes neguem a capacidade de se formar esse gestor ou corroborem a ideia de que isso é algo que deve ser moldado pelo aluno, tanto por experiências próprias como por influências externas.

Outro ponto interessante, que de certa maneira retrata a insegurança dos alunos que não tiveram aula de alguma disciplina de RSC na faculdade privada (por não ser obrigatória na época), pode ser visto nos depoimentos a seguir:

"No curso em que me formei (Administração) não posso garantir que isso aconteça, pois Responsabilidade Social não é um dos principais temas abordados e como já foi dito anteriormente, acredito que nem todos se engajem com o tema quando ele é apresentado nas aulas." (A2)

"Não sei, no meu caso sim, mas não sei se posso generalizar"

Esses participantes evidenciam nas suas declarações, por meio do uso de expressões como "não posso garantir" e "não sei se posso generalizar" o quanto era superficial a abordagem do conceito RSC na grade curricular 
anterior, e que eles apenas atribuíam o rótulo de gestor socialmente responsável às pessoas que, por seus méritos buscassem o assunto.

Quando perguntados sobre "O que poderia ser feito nas faculdades de administração para formar gestores socialmente responsáveis" foram citados três tipos de sugestões para a solução do tema. Uma solução citada pelos participantes acredita que é necessário ter mais conteúdo sobre o tema. Inclusive uma resposta exemplifica uma das recomendações feitas por Silva (2009), quando sugere a inclusão de uma matéria para o ensino de RSC e que ela seja de cunho obrigatório:

"Colocar matérias obrigatórias que abordem este tema e tendo um núcleo ativo de responsabilidade social (...) que promovesse campanhas e etc.” (B4). Outros posicionamentos citados pelos respondentes sugerem apenas a inclusão de disciplinas sobre o tema.

Descrevendo outro raciocínio citado nas sugestões, verificam-se algumas respostas que remetem à forma como o conteúdo é ensinado. Alguns participantes descrevem a necessidade de se ter um ensino mais prático e/ ou mais dinâmico, como se apresenta a seguir.

"Uma grade curricular moderna, com a matéria rsc." (B5)

"A inclusão de matérias na grade (...)." (B3)

"Uma matéria focada no assunto, e que tivesse interação com as organizações." (BI)

"Talvez disponibilizar mais matérias que abordem esse tópico, trabalhos práticos, na rua mesmo." (A7)

"Mais casos práticos e desde o início da faculdade tentar gerar profissionais com censo crítico, pendendo pelo discernimento ético de cada um.” (a6)

"Para as faculdades formarem gestores focados em responsabilidade social acho que elas deveriam fazer aulas práticas de como agir de maneira socialmente correta e mostrar o impacto que essas ações têm para uma sociedade. Acredito que todos nós absorvemos melhor uma ideologia ou informação quando a atualizamos no dia a dia e vemos o reflexo dessa atitude para o nosso cotidiano e para os que estão ao nosso redor.” (AI)

Sugere-se, avaliando as respostas, que há uma necessidade de se recriar a maneira de abordar o assunto, numa intenção de deixá-lo mais atraente, mais agradável. Expressões como "prático", "interação com organizações”, 
"promoção de campanhas", "meio de comunicação" ratificam essa necessidade de ensinar sobre o tema, mas sem massificá-lo, sem tornálo um fardo. Se fosse feito dessa forma, os alunos poderiam até ter mais interesse ao cursar essa matéria e não somente porque ela é obrigatória. Silva (2009) e Silva e Chauvel (20II) também observaram esse discurso sobre a importância do ensino da prática da RSC nas aulas das faculdades e não somente falando de teoria. 


\section{CONSIDERAÇÕES FINAIS}

A pesquisa teve o objetivo de investigar a percepção dos estudantes de Administração sobre o ensino da RSc na faculdade. Para alcançar tal objetivo, foram realizadas entrevistas em profundidade, com base em um roteiro semiestruturado, com alunos de duas faculdades no Rio de Janeiro, uma pública e outra privada.

Após analisar as respostas dadas pelos participantes, foi possível sublinhar alguns pontos relevantes sobre a percepção dos estudantes. Inicialmente, é possível observar o fato de os entrevistados se sentirem mais à vontade em relação ao tema, e, mesmo que, se equivocando na hora de definir o que significa RSC, eles, de forma geral, responderam algo relevante sobre a definição e, complementando isso, afirmam não terem dúvidas em relação ao tema. Ou seja, apesar de os estudantes acharem que entendem de fato do assunto e não terem dúvidas sobre ele, foi visto que muitos abordaram o tema de maneira superficial, não compreendendo a amplitude que o assunto tem, fato esse que também foi identificado por estudos anteriores na literatura.

Outro ponto importante a ser citado é o fato de vários alunos terem falado que o espaço dado ao tema na faculdade é insuficiente, possuindo ainda uma abordagem não planejada. Porém aqueles que tiveram a oportunidade de cursar uma matéria sobre o assunto disseram que a cursaram por ser obrigatória e não por causa de interesse, apesar de no fim terem tido a percepção geral de que o curso foi positivo. Como muitos também falaram que $\mathrm{o}$ assunto deveria ser mais abordado em relação à prática, esse deve ser um ponto que torne um curso de RSC mais atraente.

Foi possível observar um novo fator na pesquisa, que não existia nas publicações de Silva (2009) e Silva e Chauvel (20II): a inclusão da disciplina de RSC como obrigatória na grade curricular de administração da faculdade particular. Essa mudança pode ser interpretada como positiva, visto que inclusive é a demanda dos alunos, como foi falado por eles.

Portanto, a presente pesquisa trouxe contribuições no sentido de mostrar para as faculdades a importância de se ter uma disciplina voltada para o 
assunto ou, então, de uma abordagem mais planejada sobre o tema nas demais matérias. Essa é uma vontade dos próprios alunos, que enfatizam que esse espaço dado ao assunto precisa conter casos práticos, como seminários e contato com empresas que atuam de forma socialmente responsável. Mas já foi possível observar alguma mudança em relação à pesquisa anterior de Silva (2009), o que pode ser interpretado como algo positivo. É importante que as faculdades de Administração se conscientizem de que o tema precisa ser mais abordado em sala de aula.

Como sugestões para futuras pesquisas, podem ser citadas: Prosseguir com esse objetivo de pesquisa, investigando outras faculdades do Rio de Janeiro e de outros estados, para comparar como é o ensino da RSC nas diferentes regiões brasileiras; realizar pesquisas quantitativas com um maior número de entrevistados; investigar também o ponto de vista dos professores, se eles abordam o tema em sala e como avaliam essa abordagem. 


\section{REFERÊNCIAS}

AGUILERA, R. V.; RUPP, D. E.; WILLIAMS, C. A.; GANAPATHI, J. Putting the S Back in Corporate Social Responsibility: A Multilevel Theory of Social Change in Organizations. Academy of Management Review, v. 32, n. 3, p. 836-863, 2007.

ASHLEY, P. A. Ética e responsabilidade social nos negócios. São Paulo: Saraiva, 2002.

BANSAL, P.; ROTH, K. Why Companies Go Green: A Model of Ecological Responsiveness. Academy of Management Journal, v. 43, n. 4, p. 717-736, 2000.

BECKER-OLSEN, K. L.; CUDMORE, B. A.; HILL, R. P. The impact of perceived corporate social responsibility on consumer behavior. Journal of Business Research, v. 59 , p. $46-53,2006$.

BONATTO, A.; MAUSS, C. V.; MAGALHÃES, J. M. Ética e Responsabilidade Social: um estudo comparativo do balanço social da empresa Eletrocar. In: ENCONTRO NACIONAL DA ASSOCIAÇÃO NACIONAL DE PÓS-GRADUAÇÃO E PESQUISA EM ADMINISTRAÇÃO, 31., 2007, Rio de Janeiro. Anais... Rio de Janeiro: Anpad, 2007.

BOWEN, F. Corporate Social Strategy: Competing Views from Two Theories of the Firm. Journal of Business Ethics, v. 75, p. 97-113, 2007.

CANOPF, L.; PASSADOR, C.S. A responsabilidade social na graduação em administração da região sudoeste do Paraná: obrigação cumprida ou demanda atendida? In: ENCONTRO NACIONAL DA ASSOCIAÇÃO NACIONAL DE PÓSGRADUAÇÃO E PESQUISA EM ADMINISTRAÇÃO, 28., 2004. Curitiba. Anais... Curitiba: Anpad, 2004.

CARROLL, A.B. The pyramid of corporate social responsibility: toward the moral management of organizational stakeholders. Business Horizons, p. 39-48, 1991.

CHAN, R. Y. K.; WONG, Y. H.; LEUNG, T. K. P. Applying Ethical Concept to the Study of "Green" Consumer Behavior: An Analysis of Chinese Consumers' Intentions to Bring their Own Shopping Bags. Journal of Business Ethics, v. 79, p. 469-481, 2008.

ENDERLE, G.; TAVIS, L. A. A Balanced Concept of the Firm and the Measurement of Its Long-term Planning and Performance. Journal of Business Ethics, v. 17, n. 11, p. 1129-1144, 1998.

FERREIRA, D. A.; AVILA, M. G.; FARIA, M. D. Corporate social responsibility and consumers' perception of price. Social Responsibility Journal, v. 6, n. 2, p. 208-221, 2010.

FERREIRA, D. A.; FERREIRA, L.; FARIA M. D. O Ensino da Ética em Administração: Percepções e Opiniões dos Alunos. Administração: Ensino e Pesquisa, v. 12, n. 1, p. 41-64, 2011. 
FRASER, M. T. D.; GONDIM, S. M. G. Da Fala do Outro ao Texto Negociado: Discussões sobre a Entrevista na Pesquisa Qualitativa. Revista Paidéia, v. 14, n. 28, 2004.

GIL, A.C. Como elaborar projetos de pesquisa. São Paulo: Atlas, 1987.

HOND, F. D.; BAKKER, F. G. A. Ideologically Motivated Activism: How Activist Groups Influence Corporate Social Change Activities. Academy of Management Review, v. 32, n. 3, p. 901-924, 2007.

KÄRNÄ, J.; HANSEN, E.; JUSLIN, H. Social responsibility in environmental marketing planning. European Journal of Marketing, v. 37, n. 5/6, p. 848-871, 2003.

MACHADO FILHO, C. A. P. Responsabilidade Social e Governança-O Debate e as Implicações. São Paulo: Pioneira Thomson Learning, 2006.

MARQUIS, C.; GLYNN, M. A.; DAVIS, G. F. Community isomorphism and corporate social action. Academy of Management Review, v. 32, n. 3, p. 925-945, 2007.

MARREWIJK, M. Concepts and Definitions of CSR and Corporate Sustainability: Between Agency and Communion. Journal of Business Ethics, v. 44, 2003.

MATTEN, D.; MOON, J. "Implicit” and "explicit” CSR: a conceptual framework for a comparative understanding of corporate social responsibility. Academy of Management Review, v. 33, n. 2, p. 404-424, 2008.

MCWILLIAMS, A.; SIEGEL, D. Corporate social responsibility: a theory of the firm perspective. Academy of Management Review, v. 26, n. 1, p. 117-127, 2001.

MEDEIROS, C.R.O.; BORGES, J. F.; SÁ, R. C. R. A formação do administrador e a responsabilidade corporativa: ambiguidades e contradições no comportamento do futuro gestor. In: ENCONTRO NACIONAL DA ASSOCIAÇÃO NACIONAL DE PÓS-GRADUAÇÃO E PESQUISA EM ADMINISTRAÇÃO, 31., 2007, Rio de Janeiro. Anais... Rio de Janeiro: Anpad, 2007.

MELO, F. V. S.; FARIAS S. A. Sustentabilidade como Fator de Identidade de Destinos Turísticos em Websites: o Consumidor se Importa? In: ENCONTRO NACIONAL DA ASSOCIAÇÃO NACIONAL DE PÓS-GRADUAÇÃO E PESQUISA EM ADMINISTRAÇÃO. 36., 2012, Rio de Janeiro. Anais...Rio de Janeiro: Anpad, 2012.

MELO NETO, F.P.; FROES, C. Responsabilidade social \& cidadania empresarial: a administração do terceiro setor. Rio de Janeiro: Qualitymark, 2001.

NAN, X.; HEO, K. Consumer Responses to Corporate Social Responsibility (CSR) Initiatives: Examining the Role of Brand-Cause Fit in Cause-Related Marketing. Journal of Advertising, v. 36, n. 2, p. 63-74, 2007. 
ROCHA, V. A. G. A.; SILVEIRA, L. C.; WANDERLEY, L. S. O.; FRANÇA, N. R. C. Responsabilidade Social Empresarial (RSE) e Alinhamento Estratégico: Análise da Centralidade e Especificidade em Práticas Sociais Empresariais. Revista de Gestão Social e Ambiental, v. 2, n. 1, p. 3-18, 2008.

SANTOS., G. J. Cidadania Corporativa ou Ferramenta de Legitimação? - Uma Análise da Institucionalização das Práticas de Responsabilidade Social. In: ENCONTRO NACIONAL DA ASSOCIAÇÃO NACIONAL DE PÓS-GRADUAÇÃO E PESQUISA EM ADMINISTRAÇÃO, 32., 2008, Rio de Janeiro. Anais... Rio de Janeiro: Anpad, 2008.

SCHOMMER, P. C.; ROCHA, F. C. C. As Três Ondas da Gestão Socialmente Responsável no Brasil: Dilemas, Oportunidades e Limites. In: ENCONTRO NACIONAL DA ASSOCIAÇÃO NACIONAL DE PÓS-GRADUAÇÃO E PESQUISA EM ADMINISTRAÇÃO, 31., 2007, Rio de Janeiro. Anais... Rio de Janeiro: Anpad, 2007.

SEN, S.; BHATTACHARYA, C. B. Does doing good always lead to doing better? Consumer reactions to corporate social responsibility. Journal of Marketing Research, v. 3, n. 2, p. 225-243, 2001.

SERRA, F. A. R.; ALBERNAZ, A.; FERREIRA, M. P. A Responsabilidade Social como Fator na Estratégia Internacional: O Estudo do Caso Natura. Revista Eletrônica de Administração, v. 13, n. 4, 2007.

SILVA, J. M. Formação Socialmente Responsável: um Estudo sobre o Papel da Instituição de Ensino Superior na Construção de Cidadãos Comprometidos com a sociedade. In: ENCONTRO NACIONAL DA ASSOCIAÇÃO NACIONAL DE PÓSGRADUAÇÃO E PESQUISA EM ADMINISTRAÇÃO, 30., 2006, Salvador. Anais... Salvador: Anpad, 2006.

SILVA, R. C. M. Responsabilidade social no ensino em administração: um estudo exploratório sobre a visão dos estudantes de graduação. Rio de Janeiro, 2009. Dissertação (Mestrado em Administração) - PUC- Rio.

SILVA, R. C. M.; CHAUVEL, M. A. O ensino da Responsabilidade Social na graduação em Administração: Um estudo quantitativo sobre a percepção dos estudantes. REAd-Revista Eletrônica de Administração, v. 16, n. 1, 2010.

SILVA, R. C. M.; CHAUVEL, M. A. Responsabilidade social no ensino em administração: um estudo exploratório sobre a visão dos estudantes de graduação. RAP - Revista de Administração Pública, v. 45, n. 5, 2011.

SOUZA, V. S. F.; DREHER, M. T.; AMAL, M. A Influência da Responsabilidade Sócio-Ambiental no Processo de Internacionalização: o Caso da Electro Aço Altona. Revista de Ciências da Administração, v. 9, n. 19, p. 103-126, 2007. 
VOLPON, C. T.; CRUZ, E. P. A Importância da Responsabilidade Social na Fidelização dos Clientes: uma Investigação no Mercado Bancário. In: ENCONTRO NACIONAL DA ASSOCIAÇÃO NACIONAL DE PÓS-GRADUAÇÃO E PESQUISA EM ADMINISTRAÇÃO. 28., 2004, Curitiba. Anais... Curitiba: Anpad, 2004.

VIEIRA, V. A.; TIBOLA, F. Pesquisa qualitativa em marketing e suas variações: trilhas para pesquisas futuras. RAC-Revista de Administração Contemporânea, v. 9, n. $2,2005$. 


\section{DADOS DOS AUTORES}

JONATHAN PEREIRA DOS SANTOS ${ }^{\star}$ jonathan_psan@yahoo.com.br Bacharel em Adminisração pela PUC-Rio

Instituição de vinculação: Pontifícia Universidade Católica do Rio de Janeiro Rio de Janeiro/RJ - Brasil

Áreas de interesse em pesquisa: Relações Humanas.

${ }^{\star}$ Rua Marquês de São Vicente, 255 PUC-Rio Departamento de Administração-IAG

Gávea Rio de Janeiro/RJ 22451-900

\section{RENATA CÉLI MOREIRA DA SILVA renata.celi@gmail.com}

Mestre em Administração pela PUC-Rio

Instituição de vinculação: Pontifícia Universidade Católica do Rio de Janeiro

Rio de Janeiro/RJ - Brasil

Áreas de interesse em pesquisa: Marketing, Comportamento do Consumidor e Ensino em Administração. 